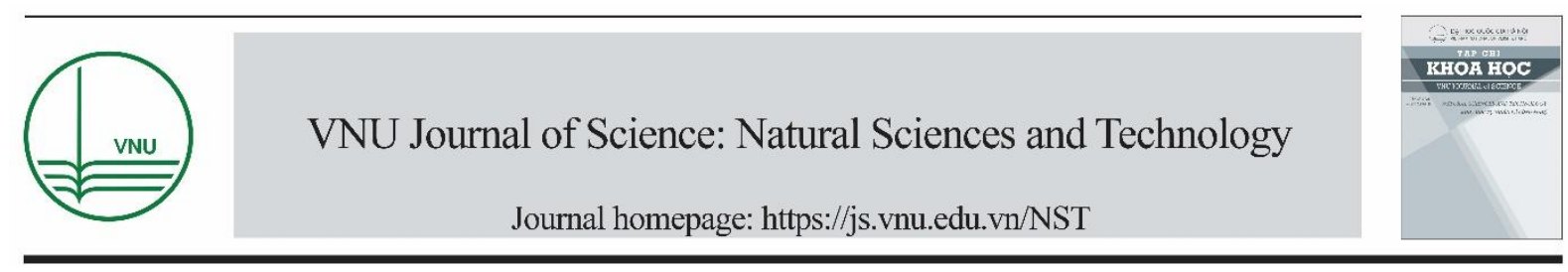

Original Article

\title{
Digestive Tract Morphology, Food Composition and Feeding Habits of the Giant Mudskipper Periophthalmodon schlosseri (Pallas, 1770) from the Coastline in Tran De, Soc Trang
}

\author{
Tran Thanh Lam ${ }^{1}$, Hoang Duc Huy ${ }^{2}$, Dinh Minh Quang ${ }^{3, *}$ \\ ${ }^{1}$ Department of Biology, School of Education, Bac Lieu University, \\ 178 Vo Thi Sau Street, Ward 8, Bac Lieu city, Bac Lieu, Vietnam \\ ${ }^{2}$ Department of Ecology and Evolutionary Biology, University of Science, Vietnam National Univeristy of \\ Ho Chi Minh, 227 Nguyen Van Cu Street, Ward 4, District 5, Ho Chi Minh City, Vietnam \\ ${ }^{3}$ Department of Biology, School of Education, Can Tho University, \\ Campus 2, 3/2 street, Xuan Khanh Ward, Ninh Kieu District, Can Tho, Vietnam
}

Received 07 March 2019

Revised 17 March 2019; Accepted 21 March 2019

\begin{abstract}
The giant mudskipper Periophthalmodon schlosseri (Pallas, 1770) is a commercial fish and distributes in estuaries and coastline in Mekong Delta, but until now there is only a study on the growth pattern and condition factor variation of this species in Vietnam. This study was conducted in the coastline at Tran De, Soc Trang from January 2018 to December 2018 with 486 individuals were analysed to provide data on gastrointestinal morphology, food and feeding habits of this species. This species is a carnivorous fish due to RLG $=0.697 \pm 0.008 \mathrm{SE}$ and feeds mainly on carbs (Uca sp., 76.06\%). Besides crabs, small fish (17.63\%), shrimps (3.85\%), detritus (1.85\%) and mollusca $(0.61 \%)$ are also found in fish stomach. Moreover, we found that 4 individuals that eat ants. The food composition of $P$. schlosseri does not vary with genders but by season. There is not different in the fullness index (FI) between genders. The FI of the immature fish is higher than that of the mature one and in the rainy season is higher than that in the dry season. The Clark index of giant mudskipper does not be significantly different between genders and seasons. The results offer scientific data on the nutritional characteristics of this species, which is the basis for research on aquaculture and sustainable exploitation of this goby.
\end{abstract}

Keywords: Clark index, food composition, fullness index, Periophthalmodon schlosseri, RLG.

\footnotetext{
${ }^{*}$ Corresponding author.

Email address: dmquang@ctu.edu.vn

https://doi.org/10.25073/2588-1140/vnunst.4871
} 


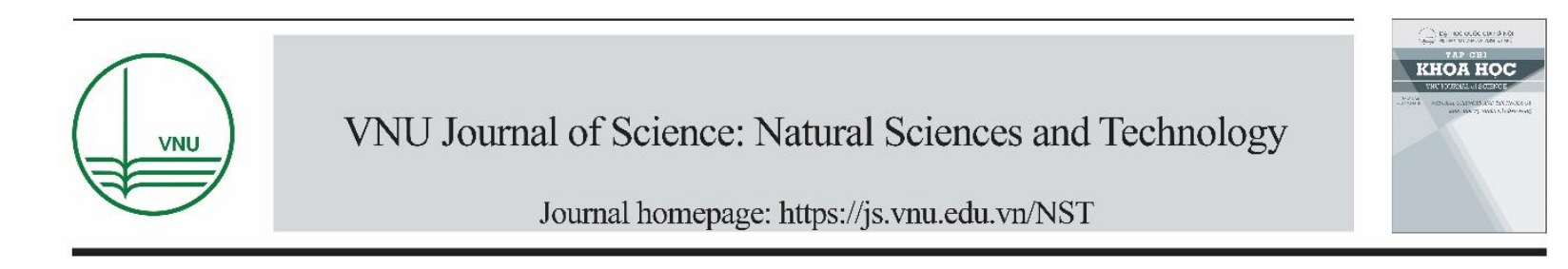

\title{
Hình thái ống tiêu hóa, tính ăn và phổ thức ăn của cá Thòi lòi Periophthalmodon schlosseri (Pallas, 1770) phân bố ven biển Trần Đề, Sóc Trăng
}

\author{
Trần Thanh Lâm ${ }^{1}$, Hoàng Đức Huy ${ }^{2}$, Đinh Minh Quang ${ }^{3, *}$ \\ ${ }^{1}$ Bộ môn Sinh học, Khoa Su phạm, Truò̀ng Đại hoc Bạc Liêu, \\ 178 Võ Thị Sáu, TP. Bạc Liêu, tỉnh Bạc Liêu, Việt Nam \\ ${ }^{2}$ Khoa Sinh họ, Truờng Đại học Khoa học Tụ nhiên, ĐHQG TP Hồ Chí Minh, \\ 227 Nguyễn Văn Cù, Phưòng 4, Quận 5, TP. Hồ Chí Minh, Việt Nam \\ ${ }^{3}$ Bộ môn Sinh hoc, Khoa Su pham, Truòng Đại học Cần Tho, \\ Khu 2 Đường 3/2, Phường Xuân Khánh, Quânn Ninh Kiều, TP. Cần Tho \\ Nhận ngày 07 tháng 3 năm 2019 \\ Chỉnh sửa ngày 17 tháng 3 năm 2019; Chấp nhận đăng ngày 21 tháng 3 năm 2019
}

\begin{abstract}
Tóm tắt: Cá Thòi lòi Periophthalmodon schlosseri (Pallas, 1770) là một loài cá có giá trị kinh tế cao, phân bố ở các cửa sông ven biển khu vực ĐBSCL, tuy nhiên hiện nay chỉ có một công bố về sự biến động tăng trưởng và hệ số điều kiện của loài này ở Việt Nam. Để đóng góp dữ liệu về hình thái đường tiêu hóa, thức ăn và tính ăn của chúng, nghiên cứu này được thực hiện ở bờ biển tại Trần Đề, Sóc Trăng từ tháng 01 năm 2018 đến tháng 12 năm 2018 với 486 cá thể được phân tích. Loài này là một loài cá ăn động vật vì $\mathrm{RLG}=0,697 \pm 0,008 \mathrm{SE}$ và thức ăn chủ yếu là còng (Uca sp., 76,06 \%). Bển cạnh thức ăn chính là còng, cá con $(17,63 \%)$, tôm $(3,85 \%)$, mùn $(1,85 \%)$ và ốc $(0,61 \%)$ cũng được tìm thấy trong đường tiêu hóa của cá. Ngoài ra, chúng tôi còn phát hiện 4 cá thể ăn kiến. Phổ dinh dưỡng của cá $P$. schlosseri không khác nhau giữa 2 giới đực và cái nhưng khác nhau theo mùa. Hệ số no (FI) không khác biệt giữa hai giới nhưng ở cá chưa thành thục cao hơn cá thành thục và ở mùa mưa cao hơn mùa khô. Hệ số độ béo Clark của cá Thòi lòi không khác biệt giữa cá đực và cá cái trong cả hai mùa. Các kết quả nhận được về đặc điểm dinh dưỡng của loài này, đã đóng góp dữ liệu khoa học cho nghiên cứu nhân nuôi nhân tạo và khai thác bền vững loài cá Thòi lòi tại khu vực nghiên cứu.
\end{abstract}

Tù khóa: Độ béo Clark, hệ số no, phổ dinh dưỡng, Periophthalmodon schlosseri, RLG.

\footnotetext{
* Tác giả liên hệ.

Địa chi email: dmquang@ ctu.edu.vn

https://doi.org/10.25073/2588-1140/vnunst.4871
} 


\section{1. Đặt vấn đề}

Loài Periophthalmodon schlosseri (Pallas, 1770) phân bố ở môi trường nước mặn và nước lợ [1]. Chúng có khả năng sống được cả môi trường cạn [2] và phân bố rộng ở bãi bồi vùng rừng ngập mặn trong khu vực Thái Bình Dương [3]. Ở Việt Nam, loài cá này phân bố từ rừng ngập mặn Cần Giờ đến Mũi Cà Mau $[4,5]$. Loài cá này có khả năng đào hang làm nơi trữ oxy và đẻ trứng trong mùa sinh sản [6-8] và có khả năng hô hấp oxy khí quyển thông qua da [9]. Đây là một loài có giá trị kinh tế ở khu vực Đông Nam Á [10]. Nghiên cứu của Ghaffar và nnk. (2006) [11] ở bãi bồi ven biển của Kuala Gula, Malaysia cho thấy, $P$. schlosseri thường ăn còng (Uca sp.) trong ngày và chuyển sang ăn côn trùng vào ban đêm khi thủy triều thấp. Chúng cũng ăn giun vào ban ngày và ban đêm khi thủy triều thấp, nhưng tần suất thấp hơn so với còng và côn trùng. Một nghiên cứu khác của Zulkifli và nnk. (2012) [12] cũng thực hiện ở Malaysia, cho thấy thức ăn của cá $P$. schlosseri thường ăn còng (Uca sp.), cá Sóc (Oryzias sp.), cá con của một số loài cá khác và một phần thức ăn không xác định được. Cụ thể, P. schlosseri cái thích ăn Oryzias sp. $(57,8 \%)$, Uca sp. $(26,7 \%)$ và con non của một số loài cá khác (6,7\%); con đực thích săn còng Uca sp. $(84,6 \%)$ và cá Sóc Oryzias sp. $(7,7 \%)$. Một số loài cá bống khác cũng thuộc nhóm ăn động vật, như cá Bống dừa Oxyeleotris urophthalmus ( $\mathrm{RLG}=0,63-0,74)$ phân bố dọc theo sông Hậu Võ Thành Toàn \& Trần Đắc Định (2014) [13] trong khu vực ĐBSCL. Trong khi đó, cá Bống sao Beleophthalmus boddarti [14] và cá Kèo vảy to Parapocryptes serperaster [15] phân bố cùng khu vực nghiên cứu nhưng thuộc nhóm cá ăn tạp. Cá Bống trứng Eleotris melanosoma phân bố ven biển huyện Trần Đề, Sóc Trăng, có RLG = $0,52 \pm 0,02[16]$ và cá Thòi lòi $P$. septemradiatus phân bố dọc sông Hậu có RLG=0,60 $\pm 0,01$ [17].

Mặc dù Periophthalmodon schlosseri có giá trị kinh tế cao ở ĐBSCL, tuy nhiên, các nghiên cứu hiện nay chỉ cung cấp những thông tin rất sơ bộ về sự phân bố [5] và sự tăng trưởng của loài cá này [18]. Hơn nữa, cũng chưa có công bố nào về đặc điểm dinh dưỡng của chúng tại ĐBSCL. Vì vậy, nghiên cứu này được thực hiện làm cơ sở cho những nghiên cứu tiểp theo về nhân nuôi nhân tạo và bảo vệ nguồn lợi của loài cá này.

\section{2. Địa điểm, thời gian và phương pháp nghiên cứu}

\section{1. Địa điểm, thời gian nghiên cứu}

Nghiên cứu được thực hiện trong 12 tháng từ tháng 01 đến tháng 12 năm 2018 tại vùng ven biển huyện Trần Đề, tỉnh Sóc Trăng (Hình 1).

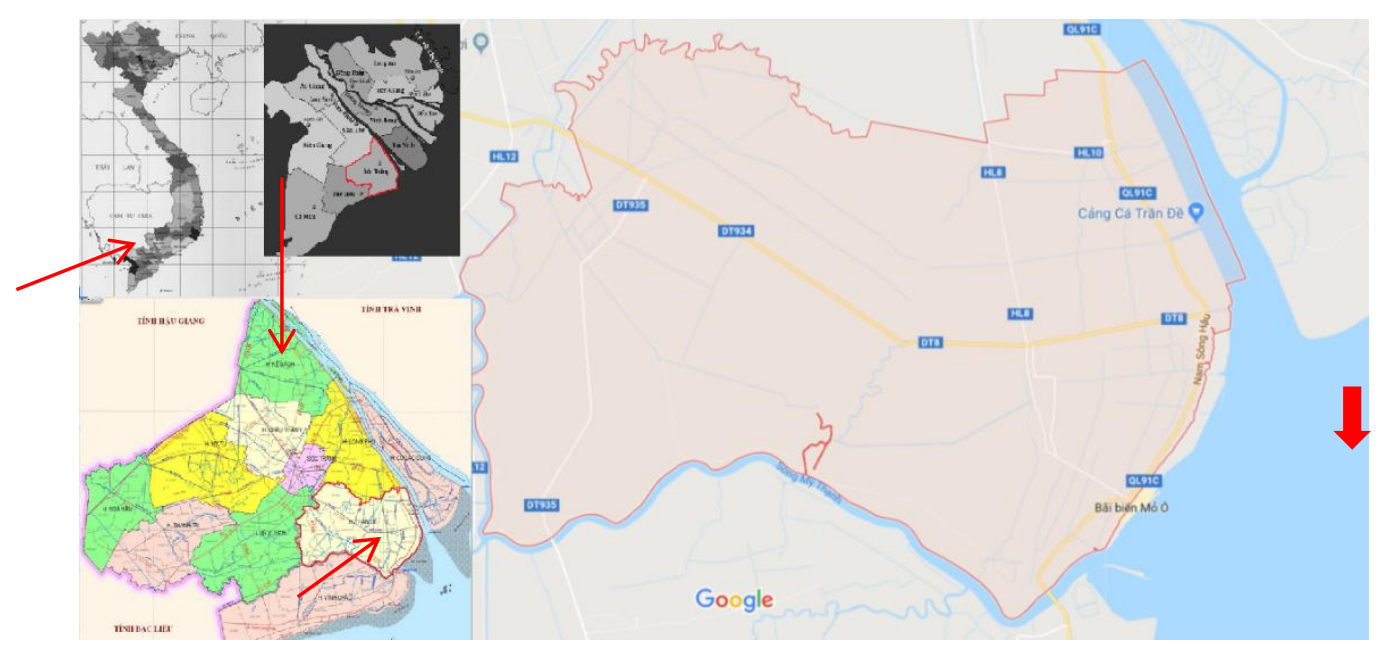

Hình 1. Sơ đồ khu vực thu mẫu (huyện Trần Đề, tỉnh Sóc Trăng).

: Địa điểm thu mẫu 


\subsection{Phưong pháp thu mẫu}

Cá được bắt bằng cách đặt lưới bên trên miệng hang hoặc bắt trực tiếp bằng tay, khi triều thấp, dọc theo bãi bồi và cửa sông ở ven biển Trần Đề, tỉnh Sóc Trăng. Mẫu cá được thu ngẫu nhiên mỗi tháng một lần vào những ngày triều kiệt với nhiều kích cỡ khác nhau. Mẫu cá được vận chuyển về Phòng thí nghiệm Động vật, Bộ môn Sư phạm Sinh học, Khoa Sư phạm, Trường Đại học Cần Thơ để phân tích sau khi được bảo quản trong dung dịch formalin 4\% (1 formalin : 9 nước) dựa trên phương pháp nghiên cứu của Dinh Minh Quang và nnk. (2017) [15].

\subsection{Phuơng pháp phân tích mẫu}

Ở phòng thí nghiệm, mẫu cá được định loại dựa vào đặc điểm hình thái ngoài được mô tả bởi Trần Đắc Định và nnk. (2013) [5] và xác định giới tính dựa vào đặc điểm hình thái của gai sinh dục (hình oval ở cái và gai nhọn ở đực) [18]. Sau đó, mẫu cá được xác định chiều dài (đến $0,1 \mathrm{~cm}$ ), khối lượng (đển $0,01 \mathrm{~g}$ ) và giải phẫu để lấy ống tiêu hóa nhằm xác định đặc điểm dinh dưỡng [19].

Chỉ số sinh trắc ruột (RLG, relative length of the gut) được dùng để xác định tính ăn của cá. Cụ thể:

RLG = Chiều dài ruột/Chiều dài toàn thân

Cá thuộc nhóm ăn động vật khi RLG $<1$, ăn tạp khi RLG $=1-3$ và ăn thực vật khi RLG > 3 [19].

Thành phần thức ăn trong ống tiêu hóa của cá được xác định đến bâc phân loại phù hợp dưới kính kính hiển vi Motic hoặc kính hiển vi soi nổi Motic [20]. Sự kết hợp hai phương pháp tần số xuất hiện (TSXH) và phương pháp trọng lượng được dùng để xác định phổ thức ăn của cá bống trứng, theo phương pháp nghiên cứu của Biswas (1993) [21]. Cụ thể:

TSXH của mỗi loại thức ăn trong ống tiêu hóa của cá được xác định bằng công thức:

$\mathrm{T}=$ [Số lượng dạ dày hiện diện thức ăn (a)/Tổng số cá thể quan sát] x 100
Trong đó, T là TSXH thức ăn loại a (\%). Cách tính tương tự cho các loại thức ăn khác còn lại.

Khối lượng của mỗi loại thức ăn trong ống tiêu hóa cá được xác định bằng công thức $K L_{a}=\frac{W_{a}}{W_{g}} \times 100$. Trong đó, KLa là tỉ lệ phần trăm khối lượng loại thức ăn thứ a hiện diện trong ống tiêu hóa của cá, Wa là khối lượng thức ăn thứ a có trong ống tiêu hóa của cá và $\mathrm{Wg}$ là khối lượng thức ăn trong ống tiêu hóa. Cách tính tương tự cho các loại thức ăn khác còn lại.

Hệ số no được xác định bằng công thức $F I=\frac{W g}{W} \times 10^{4}$ của Shorygin (1952)

Trong đố, FI là hệ số no, Wg là khối lượng thức ăn trong ống tiêu hóa và $\mathrm{W}$ là khối lượng của cá.

Hệ số béo được xác định bằng công thức Clark $=\frac{W_{0}}{T L^{3}} \times 100$ của Clark (1928) [23]. Trong đó $\mathrm{W}_{0}$ là khối lượng không nội tạng của cá và $\mathrm{TL}$ là chiều dài tổng của cá.

Xử lý số liệu: Sự biến động của chỉ số RLG theo mùa và nhóm chiều dài (dựa vào chiều dài thành thục đầu tiên để chia cá thành hai nhóm) được xác định bằng T-test. Sự tương tác của 2 nhóm nhân tố trên lên chỉ số RGL được xác định bằng 2-way ANOVA (phân tích phương sai 2 nhân tố). Sự biến động của giá trị FI và Clark theo giới tính, mùa và nhóm chiều dài cũng được xác định bằng T-test; và sự tương tác của giới tính $\times$ mùa, giới tính $\times$ nhóm chiều dài và nhóm chiều dài $\times$ mùa ảnh hưởng đến FI và Clark được xác định bằng ANOVA. Tất cả phép thử này được vận hành bằng phần mềm SPSS v.21. Điểm số của các loại thức ăn trong ống tiêu hóa (tích của TSXH và khối lượng của mỗi loại thức ăn) được dùng để kiểm tra sự ảnh hưởng của nhân tố giới tính, mùa, và nhóm chiều dài cá lên phổ dinh dưỡng bằng PERMANOVA của phần mềm PRIMER v.6 dựa trên phương pháp nghiên cứu của Dinh Minh Quang và nnk. (2017) [15]. Tất cả phép thử được xác định ở mức ý nghĩa 5\%. 


\section{Kết quả và thảo luận}

\section{1. Đặc điểm hình thái hệ tiêu hóa}

Kết quả phân tích 486 (267 cá cái và 219 cá đực) cho thấy miệng cá thòi lòi $P$. schlosseri có hàm trên nhô ra hơn so với hàm dưới và chiều dài xương hàm trên lớn hơn chiều dài của xương hàm dưới. Điều đó cho thấy cá thòi lòi có miệng dưới và thường bắt mồi ở đáy. Răng cá thòi lòi $P$. sclosseri có kích thước to, phân bố ở 2 hàm; răng hàm nhọn, sắc, phân bố không đều và xếp thành 1 hàng trên mỗi hàm (Hình 2). Đặc điểm này cho thấy cá thòi lòi $P$. sclosseri là loài ăn động vật có kích thước lớn. Lưỡi cá thòi lòi bất động, ngắn, đầu lưỡi tròn và nối liền với các cung mang của cá. Lược mang của cá thưa, nhọn, xếp khít nhau thành một hàng trên cung mang và hướng vào miệng hầu. Cá có thực quản dạng ống to, ngắn và có thể co giãn do bên trong có nhiều nếp gấp để hỗ trợ đưa thức ăn xuống dạ dày (Hình 3). Dạ dày là phần tiếp sau thực quản có hình túi ngắn, có vách dày và bên trong có nhiều nếp gấp giúp dạ dày co giản tốt và có khả năng chứa thức ăn có kích thước lớn (Hình 3 ). Là phần nối tiếp sau dạ dày, ruột có hình ống dài thẳng, gấp khúc. Ruột ngắn, có vách mỏng, nhiều nếp gấp tạo độ đàn hồi cao và có thể chứa thức ăn kích thước lớn dễ dàng (Hình 3).

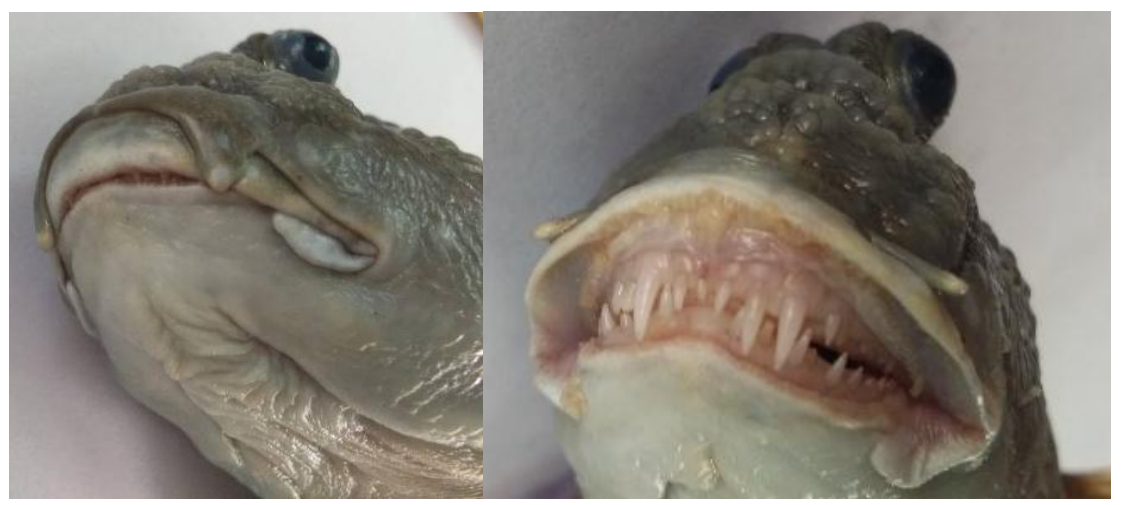

Hình 2. Miệng và răng cá $P$. sclosseri.

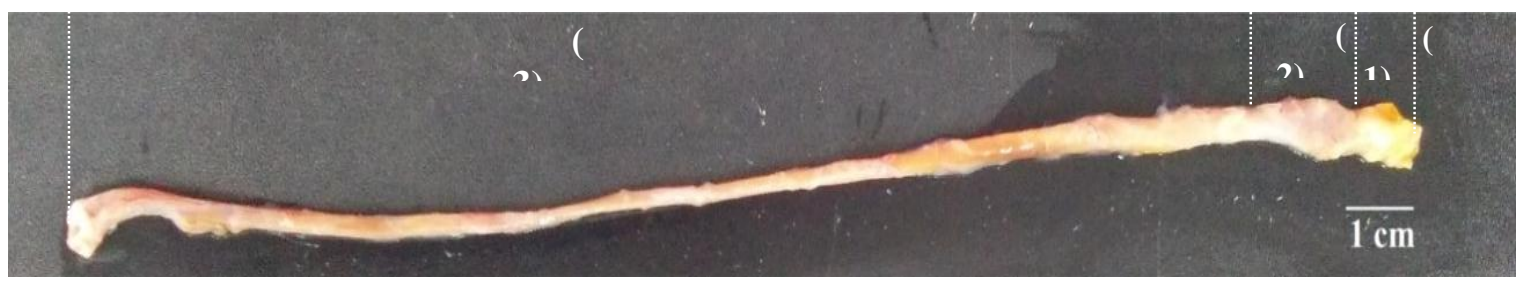

Hình 3. Thực quản (1), dạ dày (2) và ruột (3) của cá $P$. sclosseri.

\subsection{Chỉ số sinh trắc ruột RLG}

Chiều dài tổng của cá $P$. sclosseri thu được trong nghiên cứu này biến thiên từ $9,5-29,0 \mathrm{~cm}$, chiều dài ruột dao động từ 4,8 đến $27,0 \mathrm{~cm}$, trung bình $12,65 \pm 0,17 \mathrm{~cm}$; chỉ số RLG trung bình 0,6975 \pm 0,008 (Bảng 1). Như vậy, theo thang phân loại của của Nikolsky (1963) [19], cá thòi lòi thuộc nhóm cá ăn động vật. Điều này còn được khẳng định bằng sự xuất hiện của phần lớn còng và tôm, cá con trong ống tiêu hóa của cá $P$. sclosseri. Kết quả này giống với nghiên cứu trước của Ghaffar và nnk. (2006) [11] và Zulkifli và nnk. (2012) [12] và giống với một số loài cá bống khác như cá Bống dừa Oxyeleotris urophthalmus phân bố dọc theo sông Hậu [13], cá Bống trứng Eleotris melanosoma [16], cá Thòi lòi P. septeradiatus [17]. 
Bảng 1. Chỉ số sinh trắc RLG của cá $P$. sclosseri

\begin{tabular}{lc}
\hline \multicolumn{1}{c}{ Đại lượng } & Trung bình $\pm \mathrm{SE}$ \\
\hline Chiều dài ruột $(\mathrm{Lr})$ & $12,65 \pm 0,17$ \\
Chiều dài tồng $(\mathrm{Lt})$ & $18,15 \pm 0,13$ \\
Lr/Lt (RLG) & $0,697 \pm 0,008$ \\
\hline
\end{tabular}

Kết quả thống kê cho thấy chỉ số RLG của cá chưa thành thục $(0,7003 \pm 0,0087 \mathrm{SE})$ lớn hơn cá thành thục $(0,6891 \pm 0,0174)$, mùa khô $(0,7367 \pm 0,0139)$ cao hơn so với mùa mưa $(0,6795 \pm 0,0093)$, tuy nhiên sự khác biệt này không có ý nghĩa về mặt thống kê $(\mathrm{P}>0,05)$. Như vậy, tính ăn của cá Thòi lòi $P$. sclosseri ở Trần Đề (Sóc Trăng) không phụ thuộc vào giai đoạn sinh trưởng và thời gian trong năm. Tương tự, tính ăn của cá Thòi lòi $P$. septemradiatus [17], cá Bống dừa $O$. urophthalmus phân bố dọc theo sông Hậu [16] và cá Kèo vảy to $P$. serperaster trong cùng khu phân bố [15] cũng không thay đổi theo sự phát triển của cá.

\subsection{Phổ dinh duõng}

Phổ dinh dưỡng của cá Thòi lòi P. sclosseri ở Trần Đề có 5 nhóm chính, bao gồm cá con của một số loài (Plotosus canius, Trypauchen sp., Arius sp., Pseudapocryptes elongatus,...), tôm (Metapenaeus sp.), ốc (Littoraria sp.), còng (Uca sp.) và mùn bã hữu cơ. Trong đó, còng chiếm tỉ lệ cao nhất $76,06 \%$, tiếp đến là cá $17,63 \%$, tôm là $3,85 \%$, mùn bã hữu cơ $1,85 \%$ và ốc là $0,61 \%$. Ngoài ra, nghiên cứu này đã ghi nhận được 4 ruột cá có kiến trong tổng số 462 ruột cá có chứa thức ăn, chiếm tỉ lệ $0,00022 \%$ (Hình 4). Điều này cho thấy còng là nhóm đóng góp rất lớn vào trong phổ dinh dưỡng của cá Thòi lòi P. sclosseri trong nghiên cứu này. Kết quả này không khác biệt nhiều với nghiên cứu của Zulkifli và nnk. (2012) [12] khi phổ thức ăn của cá P. schlosseri cũng gồm chủ yếu cá Sóc Oryzias sp. và còng Uca sp. Tuy nhiên, phổ thức ăn cá Thòi lòi P. sclosseri ở Trần Đề không có giun như nghiên cứu của Ghaffar và nnk. (2006) [11] ở bãi bồi ven biển của Kuala Gula, Malaysia. Trong quá trình nghiên cứu, tác giả và nhóm nghiên cứu chưa phát hiện giun ở bãi bồi ven biển huyện Trần Đề, vì vậy không phát hiện giun trong ống tiêu hóa của cá P. schlosseri ở đây.

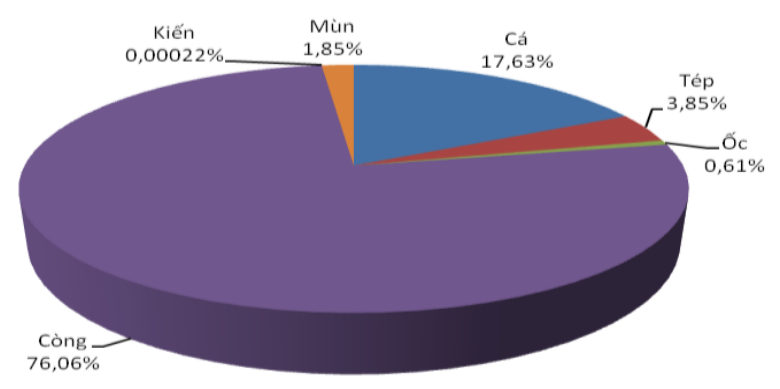

Hình 4. Phổ dinh dưỡng cá Thòi lòi $P$. schlosseri.

Cá Bống sao Boleophthalmus boddarti và cá Thòi lòi $P$. schlosseri sống cùng sinh cảnh nhưng cá Bống sao là loài ăn tạp (RLG>1), với Bacillariophyta $(82,97 \%)$ và mùn bã hữu cơ $(13,26 \%)$ là thức ăn chính của cá Bống sao [14]. Do đó, 2 loài này không có sự cạnh tranh thức ăn.

Bảng 2. Phổ dinh dưỡng của cá $P$. sclosseri theo giới tính và theo mùa

\begin{tabular}{lllll}
\hline \multirow{2}{*}{ Thành phần thức ăn } & \multicolumn{3}{l}{ Theo giới tính } & \multicolumn{2}{l}{ Theo mùa } \\
\cline { 2 - 5 } & Cá đực $(\%)$ & Cá cái $(\%)$ & Mùa khô $(\%)$ & Mùa mưa (\%) \\
\hline Cá & 18,77 & 16,62 & 11,86 & 20,28 \\
Tôm & 3,43 & 4,21 & 5,80 & 3,15 \\
Ốc & 0,53 & 0,67 & 0,80 & 0,49 \\
Còng & 75,96 & 76,25 & 81,25 & 73,31 \\
Kiến & 0,0011 & 0,00 & 0,00015 & 0,00025 \\
Mùn bã hữu cơ & 1,30 & 2,24 & 0,29 & 2,76 \\
\hline
\end{tabular}


Phổ thức ăn của cá cái và đực đều có 5 nhóm thức ăn: Cá con, tôm, ốc, còng và mùn bã hữu cơ nhưng giữa cá đực và cá cái không có sự khác biệt về mặt thống kê $(\mathrm{P}>0,05)$ của 5 nhóm thức ăn này. Tuy nhiên, chỉ có 4 cá đực có kiến trong thành phần thức ăn, nhưng cá cái không có. Do đó không thể kết luận chỉ có cá đực mới ăn kiến. Kết quả này khác với nghiên cứu của Zulkifli và nnk. (2012) [12], khi P. schlosseri cái thích ăn Oryzias sp. (57,8\%), Uca sp. (26,7\%) nhưng cá đực thích ăn còng $U c a$ sp. $(84,6 \%)$ hơn Oryzias sp. $(7,7 \%)$.

Phổ dinh dưỡng của cá $P$. schlosseri không khác nhau giữa cá đực và cá cái nhưng khác nhau theo mùa. Ốc, mùn bã hữu cơ và cá là ba loại thức ăn của cá $P$. schlosseri có sự khác biệt giữa hai mùa $(\mathrm{P}<0.05)$, trong đó, cá và mùn bã hữu cơ chiếm tỉ lệ nhiều hơn trong mùa khô (Bảng 2). Vào mùa mưa, lượng nước mưa có thể làm thay đổi tính chất của thủy vực từ lợ sang ngọt, nước sông từ vùng thượng lưu đổ về các cửa sông ven biển mang một lượng lớn các chất dinh dưỡng: phù sa, các xác bã động thực vật, các động vật phù du, tảo,... là điều kiện thuận lợi cho sự phát triển của các loài thủy sinh. Bên cạnh đó, mùa mưa là mùa sinh sản của nhiều loài cá, nên cá thòi lòi cũng ăn nhiều cá con hơn.

\subsection{Hệ số no và hệ số béo}

Hệ số no của cá cái $(73,48 \pm 4,18 \mathrm{SE}, \mathrm{n}=$ 267) cao hơn so với cá đực $(72,60 \pm 5,30 \mathrm{SE}, \mathrm{n}$ = 219), tuy nhiên, sự khác biệt này không có ý nghĩa thống kê $(P>0,05)$. Nhưng hệ số no có sự khác biệt theo mùa và giai đoạn phát triển. Hệ số no của cá chưa thành thục $(82,14 \pm 4,11 \mathrm{SE}, \mathrm{n}=$ 364) cao hơn nhiều so với cá thành thục $(46,06$ $\pm 3,98 \mathrm{SE}, \mathrm{n}=122$ ); điều này cho thấy cá chưa thành thục ăn nhiều hơn cá thành thục, đặc biệt cá cái đang ở giai đoạn 4 và 5 , cá sắp hoặc đang đẻ nên giảm cường độ bắt mồi. Hệ số no của cá vào mùa mưa $(86,47 \pm 4,02 \mathrm{SE}, \mathrm{n}=333)$ cao hơn mùa khô $(43,96 \pm 5,13 \mathrm{SE}, \mathrm{n}=153)$. Điều này cho thấy lượng thức ăn trong mùa mưa cao hơn nhiều so với mùa khô. Hệ số no ở cá Thòi lòi thấp hơn nhiều so với cá Bống trứng Eleotris melanosoma [1] và cá Bống mít Stigmatogobius pleurostigma [24] tại cùng khu vực nghiên cứu (Bảng 3). Tuy nhiên, hệ số no của hai loài này không có sự khác biệt giữa hai giới và hai mùa $[16,24]$.

Bảng 3. Hệ số no của một số loài cá bống tại Trần Đề, Sóc Trăng

\begin{tabular}{lccccl}
\hline \multicolumn{1}{c}{ Loài } & Cá đực & Cá cái & Mùa mưa & Mùa khô & \multicolumn{1}{c}{ Nguồn } \\
\hline $\begin{array}{l}\text { Periophthalmodon } \\
\text { schlosseri }\end{array}$ & $72,60 \pm 5,30$ & $73,48 \pm 4,18$ & $86,47 \pm 4,02$ & $43,96 \pm 5,13$ & Nghiên cứu này \\
$\begin{array}{l}\text { Eleotris melanosoma } \\
\begin{array}{l}\text { Stigmatogobius } \\
\text { pleurostigma }\end{array}\end{array}$ & $183,82 \pm 42,11$ & $159,08 \pm 14,85$ & $177,04 \pm 29,81$ & $143,19 \pm 24,05$ & $\begin{array}{l}\text { Dinh Minh Quang và nnk. } \\
(2017) \text { [16] }\end{array}$ \\
\hline
\end{tabular}

Hệ số béo Clark của cá cái $(0,882 \pm 0,005$ $\mathrm{SE})$ gần tương đương với hệ số này ở cá đực $(0,891 \pm 0,005 \mathrm{SE}, \mathrm{P}>0,05)$; tương tự, hệ số này không khác biệt giữa mùa mưa $(0,8844 \pm 0,005)$ và mùa khô $(0,8894 \pm 0,005, P>0,05)$. Mặc dù, hệ số béo của cá chưa thành thục $(0,891 \pm 0,004)$ cao hơn cá thành thục $(0,869 \pm 0,008)$ nhưng không có ý nghĩa thống kê $(\mathrm{P}>0,05)$. Điều này không phù hợp với hệ số no. Tương tự cá Thòi lòi, hệ số béo Clark của cá Bống mít Stigmatogobius pleurostigma tại cùng khu vực nghiên cứu cũng không khác biệt giữa hai giới và hai mùa trong năm [25].

\section{Kết luận}

Cá Thòi lòi $P$. schlosseri thuộc nhóm cá ăn động vật và bắt mồi ở tầng nước đáy. Có 5 nhóm thức ăn chính được tìm thấy trong ống tiêu hóa của cá $P$. schlosseri như cá con, tôm, ốc, còng và mùn bã hữu co; chỉ ghi nhận được 4 trường hợp ăn kiến. Tính ăn của cá không có sự thay đồi theo 
giới tính và nhóm chiều dài cá. Hệ số no của cá thòi lòi cái và cá đực không khác biệt, nhưng cá chưa thành thục cao hơn cá thành thục và mùa mưa cao hơn mùa khô. Hệ số béo Clark của cá Thòi lòi không khác biệt giữa cá đực và cá cái trong cả hai mùa. Kết quả nghiên cứu đã bổ sung dẫn liệu khoa học về đặc điểm hình thái ống tiêu hóa, tính ăn và phổ dinh dưỡng cho loài này và làm cơ sở cho những nghiên cứu tiếp theo về nhân nuôi nhân tạo chúng, nhằm đảm bảo khai thác bền vững nguồn lợi của loài cá này trong tương lai.

\section{Tài liệu tham khảo}

[1] E.O. Murdy, A taxonomic revision and cladistic analysis of the oxudercine gobies (Gobiidae, Oxudercinae), Records of the Australian Museum, Sydney, Australia, 1989, Supplement 11. http://dx.doi.org/10.3853/j.0812-7387.11.1989.93

[2] D.A. Clayton, Mudskippers, Oceanography and Marine Biology: An Annual Review 31 (1993) 507-577.

[3] R. Froese, D. Pauly, FishBase, World Wide Web electronic publication, https://www.fishbase.in/ summary/Periophthalmodon-schlosseri.html, 2019 (Truy cập: 13/03/2019).

[4] T.X. Tám, P.V. Ngọt, N.T. Hà, Góp phần nghiên cứu về đa dạng thành phần loài cá ở hệ sinh thái rừng ngập mặn Cần Giờ, Thành phố Hồ Chí Minh, Tạp chí Khoa học Đại học Sư phạm Thành phố Hồ Chí Minh 40 (2012) 91-104.

[5] T.Đ. Định, S. Koichi, N.T. Phương, H.P. Hùng, T.X. Lợi, M.V. Hiếu, U. Kenzo, Mô tả định loại cá Đồng bằng sông Cửu Long, Việt Nam, NXB Đại học Cần Thơ, Cần Thơ, 2013.

[6] A. Ishimatsu, Y. Hishida, T. Takita, T. Kanda, S. Oikawa, T. Takeda, K.K. Huat, Mudskippers store air in their burrows, Nature, 391 (1998) 237-238. http://dx.doi.org/10.1038/34560.

[7] A. Ishimatsu, N.M. Aguilar, K. Ogawa, Y. Hishida, T. Takeda, S. Oikawa, T. Kanda, K.K. Huat, Arterial blood gas levels and cardiovascular function during varying environmental conditions in a mudskipper, Periophthalmodon schlosseri, Journal of Experimental Biology, 202 (1999) 1753-1762.

[8] A. Ishimatsu, T. Takeda, Y. Tsuhako, T.T. Gonzales, K.H. Khoo, Direct evidence for aerial egg deposition in the burrows of the Malaysian mudskipper, Periophthalmodon schlosseri, Ichthyological Research, 56 (2009) 417-420. https://doi.org/10.1007/s10228-009-0113-2

[9] J. Zhang, T. Taniguchi, T. Takita, B.A. Ali, A study on the epidermal structure of Periophthalmodon and Periophthalmus mudskippers with reference to their terrestrial adaptation, Ichthyological Research 50 (2003) 310-317. https://doi.org/10.1007/s10228-00300173-7.

[10] Y.K. Ip, S.F. Chew, A.L.L. Lim, W.P. Low, The mudskipper, In "Essays in Zoology, Papers Commemorating the $40^{\text {th }}$ Anniversary of Department of Zoology" National University of Singapore Press, Singapore, 83-95, 1990.

[11] M.A. Ghaffar, F. Yakob, S.M. Nor, A. Arshad, Foraging behavior and food selection of giant mudskipper (Periophthalmodon schlosseri) at Kuala Gula, Matang Mangrove Reserve, Perak, Malaysia, Coastal Marine Science 30 (2006) 263267. https://doi.org/10.15083/00040787

[12] S.Z. Zulkifli, F. Mohamat-Yusuff, A. Ismail, N. Miyazaki, Food preference of the giant mudskipper Periophthalmodon schlosseri (Teleostei: Gobiidae), Knowledge and Management of Aquatic Ecosystems, (2012) 07p00-07p10. https://doi.org/10.1051/kmae/2012013.

[13] V.T. Toàn, T.Đ. Định, Nghiên cứu đặc điểm dinh dưỡng cá bống dừa (Oxyeleotris urophthalmus) phân bố dọc theo sông Hậu, Tạp chí Khoa học Đại học Cần Thơ, Thủy sản (2014) 192-197.

[14] D.M. Quang, Preliminary study on dietary composition, feeding activity and fullness index of Boleophthalmus boddarti in Mekong Delta, Vietnam, Tạp chí Sinh học 37 (2015) 252-257. https://doi.org/10.15625/0866-7160/v37n2.6599.

[15] D.M. Quang, J.G. Qin, S. Dittmann, T.D. Dinh, Seasonal variation of food and feeding in burrowing goby Parapocryptes serperaster (Gobiidae) at different body sizes, Ichthyological Research 64 (2017) 179-189. https://doi.org/10. 1007/s10228-016-0553-4.

[16] Đ.M. Quang, N.T. Duy, D. Sóc, Tính ăn và phổ thức ăn của cá bống trứng Eleotris melanosoma ở ven biển tỉnh Sóc Trăng, Hội nghị Khoa học toàn quốc về Sinh thái và Tài nguyên Sinh vật lần thứ $7, \mathrm{NXB}$ Khoa học Tự nhiên và Công nghệ, 1873-1879, 2017.

[17] D.M. Quang, T.T. Lam, N.T.K. Tien, The relative gut length and gastro-somatic indices of the 
mudskipper Periophthalmodon septemradiatus (Hamilton, 1822) from the Hau River, VNU Journal of Science: Natural Sciences and Technology $34 \quad$ (2018) 75-83. https:// doi.org/10.25073/2588-1140/vnunst.4775.

[18] D.M. Quang, Growth and body condition variation of the giant mudskipper Periophthalmodon schlosseri in dry and wet seasons, Tạp chí Sinh học 38 (2016) 352-358. https://doi.org/10.15625/0866-7160/v38n3.7425.

[19] G.V. Nikolsky, Ecology of fishes, Academic Press, London, United Kingdom, 1963.

[20] N.V. Hanh, N.N. Châu, N.Đ. Tứ, N.T. Hiền, A. Vanreusel, N. Smol, Động vật đáy hệ sinh thái rừng ngập mặn Cần Giờ, NXB Khoa học Tự nhiên và Công nghệ, Hà Nội, 2013.

[21] S.P. Biswas, Manual of Methods in Fish Biology, South Asian Publishers, New Delhi, 1993.
[22] A.A. Shorygin, Feeding and trophic relations of fishes of the Caspian Sea, Pishchepromizdat, Moscow, 1952.

[23] F.N. Clark, The weight-length relationship of the California Sardine (Sardina carulea) at San Pedro, Division of fish and game of California, California, 1928.

[24] Đ.M. Quang, T.T.D. My, Hình thái ống tiêu hóa, tính ăn và phổ thức ăn của cá bống mít Stigmatogobius pleurostigma (Bleeker, 1849) phân bố ven biển Sóc Trăng, Tạp chí Khoa học ĐHQGHN: Khoa học Tự nhiên và Công nghệ 34 (2018) 46-55. https://doi.org/10.25073/25881140/vnunst.4740.

[25] N.M. Tuấn, T.Đ. Định, Nghiên cứu tính ăn và phổ thức ăn cá bống cát Glossogobius aureus Akihito \& Meguro, 1975, Tạp chí Khoa học Trường Đại học Trà Vinh 29 (2018) 63-70. 